\title{
Late ocular manifestations in neonatal herpes simplex infection
}

\author{
AHTI TARKKANEN AND LEILA LAATIKAINEN \\ From the Helsinki University Eye Hospital
}

SUMMARY Five patients who had had neonatal herpes simplex virus infection were re-examined at ages that varied from 6 to 9 years. In all of them the diagnosis had been supported by virus isolation and antibody titration, and herpes virus type 2, the genital strain, had been the causative agent. Only 1 of the patients was mentally retarded. Three of the patients had manifest squint, and only 1 patient had normal visual acuity in both eyes. The fundus changes varied from atrophy of the retinal pigment epithelium in 3 patients to atrophy of the optic disc in 2 eyes and extreme tortuosity of the retinal arterioles and veins in 1 patient. One patient developed bilateral retinitis with exudation into the vitreous at the age of 5 years. Fluorescein angiography of this patient showed peripheral vascular closure and preretinal neovascularisation, with leakage in both eyes. This may have been due to chronic retinal vasculitis; haemorrhagic infarction may have induced the damage to retinal tissues. Laser photocoagulation resulted in slight improvement of the visual acuity, clearing of the vitreous, and decrease of the fluorescein leakage.

Ocular manifestations of herpes simplex virus (HSV) infection in the newborn include conjunctivitis, keratitis, cataract, and chorioretinitis (Hagler et al., 1969; Nahmias and Hagler, 1972). In a series of 297 cases of neonatal HSV infection $17 \%$ had ocular involvement. Microphthalmia, keratitis, or conjunctivitis were noted within the first day of life, while some infants had cataract, chorioretinitis, or optic atrophy later. Corneal scars or recurrent keratitis were also important sequelae (Nahmias et al., 1976). Chorioretinitis may have a variety of appearances, though histopathological studies have shown that the process is limited to the retina and the pigment epithelium, with minimal secondary infiltration of the choroid and the vitreous (Cogan et al., 1964; Young et al., 1965; Cibis, 1975).

Published reports suggest that retinal changes in infants with mild herpes infection without evidence of central nervous system involvement are rare, and little information is available on possible late ocular manifestations of neonatal HSV infection. We therefore now describe the findings of an ophthalmic follow-up study on children surviving after neonatal HSV infection.

\section{Patients and methods}

The study is of 5 children who had suffered a

Address for reprints: Dr A. Tarkkanen, Helsinki University Eye Hospital, Haartmaninkatu 4, 00290 Helsinki 29, Finland neonatal HSV infection. The birth weight and the duration of the pregnancy of each patient are listed in Table 1. The diagnosis had been made by virus isolation and antibody titration. Herpes virus type 2 was the causative agent in all cases where the type had been determined. Because the early symptoms and the clinical and virological studies of these patients have earlier been reported in detail (Pettay et al., 1972) these aspects will be reviewed only briefly in this paper.

At the time of the follow-up study the patients were 6 to 9 years of age. In 4 cases the general physical and mental development had been unremarkable; one patient was mentally retarded. All patients received a thorough ophthalmic examination, including fundus photography and in one case fluorescein angiography as well.

Table 1 Birth particulars of the 5 cases

\begin{tabular}{lllll}
\hline Case & Sex & $\begin{array}{l}\text { Age at } \\
\text { follow-up } \\
\text { (years) }\end{array}$ & $\begin{array}{l}\text { Birth weight } \\
(\mathrm{g})\end{array}$ & $\begin{array}{l}\text { Duration of } \\
\text { pregnancy } \\
\text { (weeks) }\end{array}$ \\
\hline 1 & M & 6 & 1600 & 36 \\
2 & F & 7 & 3600 & 44 \\
3 & F & 9 & 2320 & 33 \\
4 & F & 7 & 2440 & 36 \\
5 & M & 9 & 3290 & 40 \\
\hline 68 & & & &
\end{tabular}


Fig. $1 a, b$ Case 3 (a) Right fundus shows an elliptical optic disc and atrophic retinal pigment epithelium.

(b) Left disc and macular area are covered by a thick fibrovascular preretinal fold
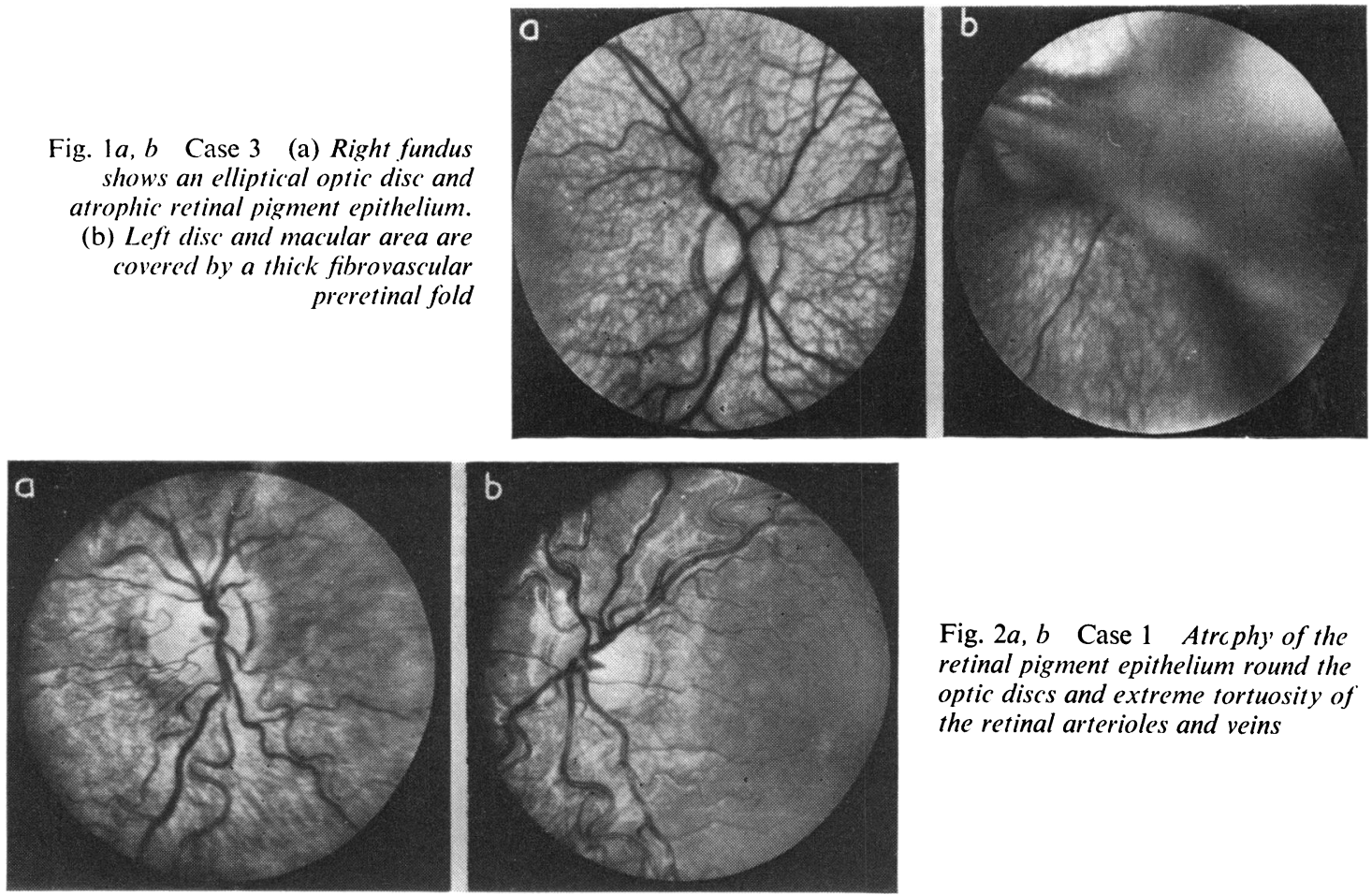

Fig. $2 a, b$ Case 1 Atrcphy of the retinal pigment epithelium round the optic discs and extreme tortuosity of the retinal arterioles and veins
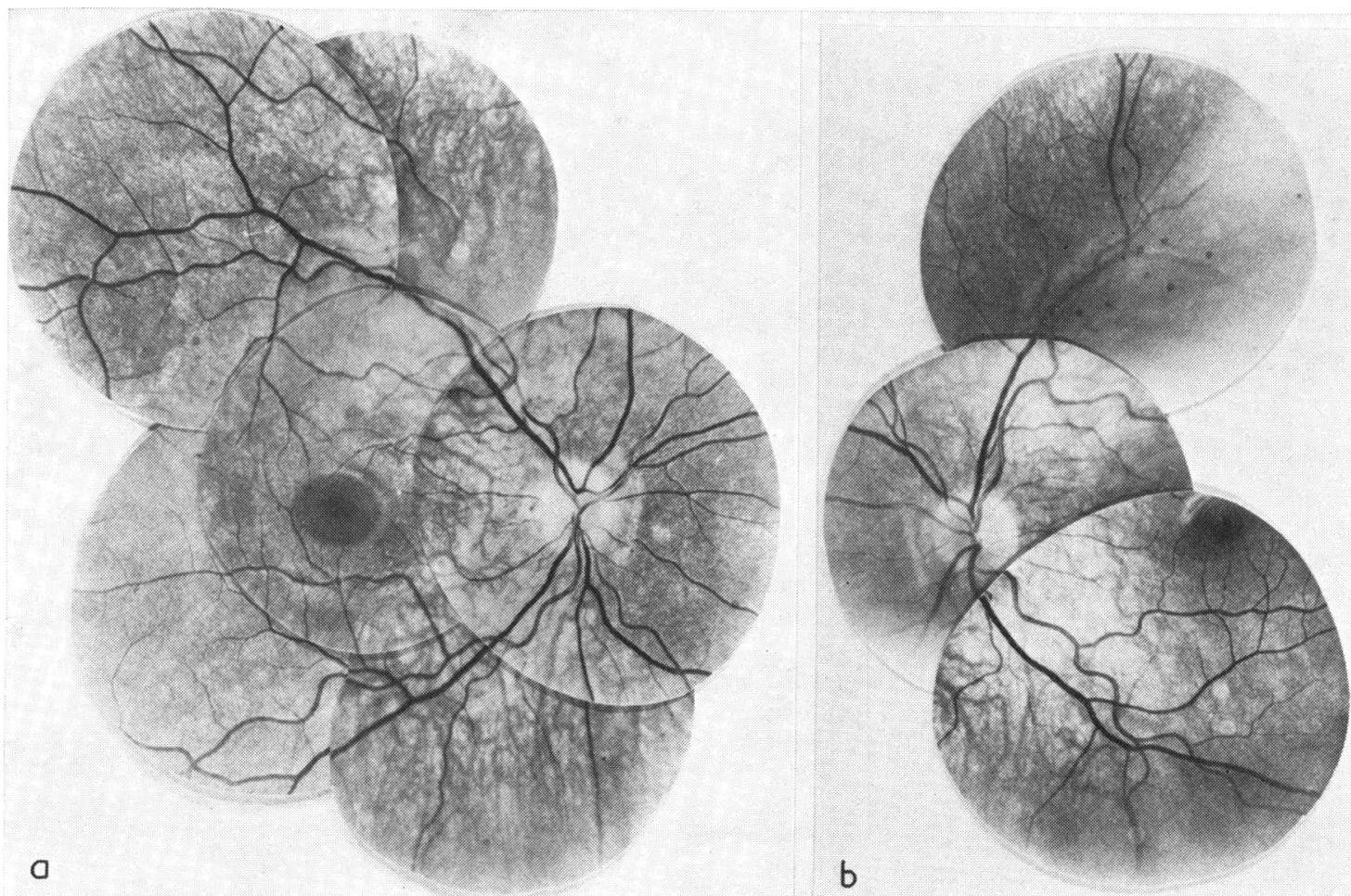

Fig. $3 a, b$ Case 5 Atrophy of the retinal pigment epithelium in the central areas 
Table 2 Late manifestations of neonatal herpes simplex virus infection

\begin{tabular}{|c|c|c|c|c|c|c|c|c|c|}
\hline \multirow{2}{*}{ Case } & \multicolumn{2}{|c|}{ Visual acuity } & \multicolumn{2}{|l|}{ Refraction } & \multirow{2}{*}{ General comments } & \multicolumn{2}{|l|}{ Lens } & \multirow{2}{*}{$\frac{\text { Vitreous }}{\text { Riglit cye }}$} & \multirow{2}{*}{ Left eye } \\
\hline & Right eye & Left eye & Right eye & Left eye & & Riglit eye & Left cye & & \\
\hline 1 & 0.5 & $0 \cdot 5$ & $+1 \cdot 50$ & $+1 \cdot 50$ & Mentally retarded & Clear & Clear & Clear & Clear \\
\hline 2 & $0 \cdot 15$ & $1 \cdot 0$ & $+2 \cdot 0$ & $+2 \cdot 25$ & Right exotropia & Clear & Clear & Clear & Clear \\
\hline 3 & c.í. & c.f. & +3.0 & $+3 \cdot 0$ & Left esotropia & Clear & Clear & Clear & $\begin{array}{l}\text { Fibrovascular } \\
\text { fold }\end{array}$ \\
\hline 4 & $0 \cdot 7$ & $1 \cdot 0$ & $+2 \cdot 25$ & $+2 \cdot 25$ & Alternating exotropia & Clear & Clear & $\begin{array}{l}\text { Inflammatory } \\
\text { exudation }\end{array}$ & Clear \\
\hline 5 & $1 \cdot 0$ & $1 \cdot 0$ & $-1 \cdot 25$ & $-1 \cdot 0$ & & Clear & Clear & Clear & Clear \\
\hline
\end{tabular}

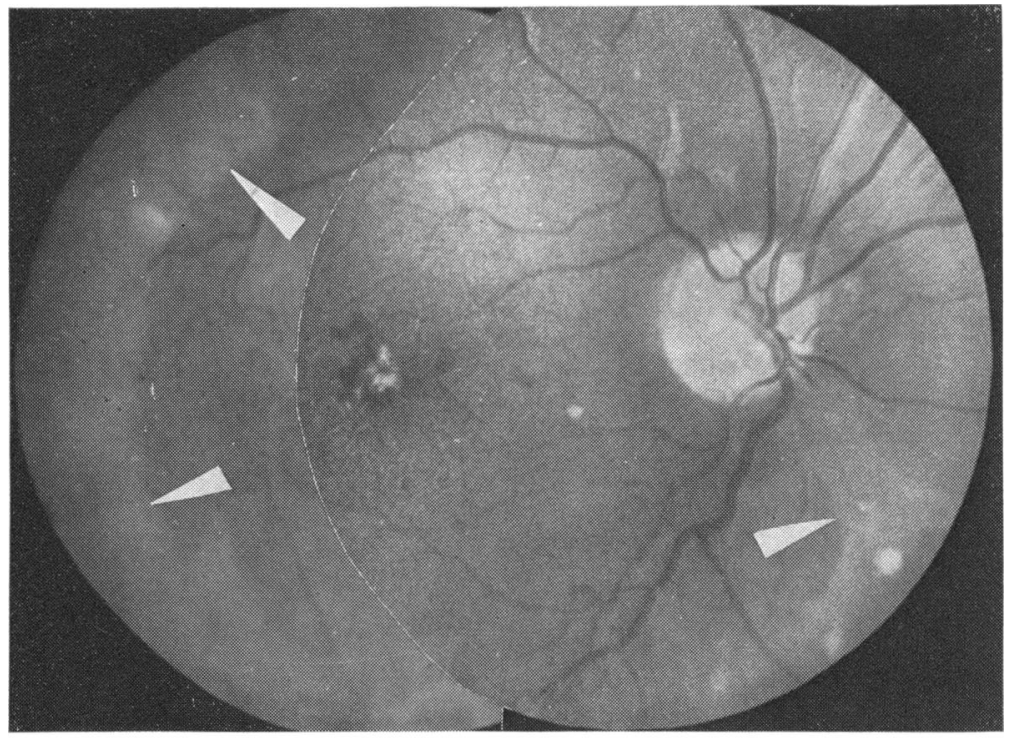

Fig. 4a, $b$ Case 4 . (a) Right eye. Fundus photograph showing pale disc, attenuated arteries, and greyish preretinal membrane surrounding the posterior pole (arrows). Dilated capillaries and intraretinal white exudates in the centre of the macula. (b) Left eye. Comparable picture, changes less pronounced

$4 a$

\section{Results}

The visual acuities and refractions at the follow-up examination are listed in Table 2. Only 1 patient (case 5) had normal visual acuity in both eyes. The refractions were not remarkable, but 3 of the 5 patients had manifest squint. The ocular tensions were within normal limits. The lenses were clear, but the vitreous contained inflammatory exudation in 1 patient (case 4) and a thick fibrovascular fold in one (case 3, Fig. 1a, $b$ ).

The optic discs were pale in 2 eyes (cases 2 and 3 ). The retinal manifestations included atrophy of the retinal pigment epithelium, especially round the optic disc on 3 patients (cases 1, 3, and 5; Figs. $2 a, b ; 1 a$;
$3 a, b)$ allowing visualisation of the choroidal vascular system and extreme tortuosity of the retinal arterioles and veins (Fig. 2a,b). The inflammatory manifestations in case 4 are described in the following case report.

\section{CASE REPORT}

Case 4 was a girl with a birth weight of $2440 \mathrm{~g}$, prematurely born at 36 weeks gestation. At birth she had several groups of vesicles on both arms as well as several pale round 5-mm spots, many of them surrounded by a ring of crusts, on the back and on both sides. Her general condition was good, no other signs of infection were observed, and later development was normal. The virus (herpes virus 


\begin{tabular}{|c|c|c|c|}
\hline \multicolumn{2}{|l|}{ Optic disc } & \multicolumn{2}{|l|}{ Retina } \\
\hline Right eye & Left eye & Right eye & Left eye \\
\hline Normal & Normal & $\begin{array}{l}\text { Atrophy of the pigment epithelium around } \\
\text { the optic disc, highly tortuous arterioles } \\
\text { and veins }\end{array}$ & As the right eye \\
\hline $\begin{array}{l}\text { Pale, anomalous almost like } \\
\text { coloboma }\end{array}$ & Normal & Normal & Normal \\
\hline Normal & Pale, atrophic & $\begin{array}{l}\text { Atrophy of the retinal pigment epithelium } \\
\text { around the optic disc }\end{array}$ & Fibrovascular fold extending to the vitreous \\
\hline Normal & Normal & $\begin{array}{l}\text { Posterior oedema, attenuated arteries, } \\
\text { dilated capillaries and intraretinal } \\
\text { white exudates }\end{array}$ & $\begin{array}{l}\text { Glistening retina, attenuated arteries, some } \\
\text { faint greyish spots }\end{array}$ \\
\hline Normal & Normal & $\begin{array}{l}\text { Atrophy of the retinal pigment epithelium } \\
\text { around the optic disc }\end{array}$ & As the right eye \\
\hline
\end{tabular}

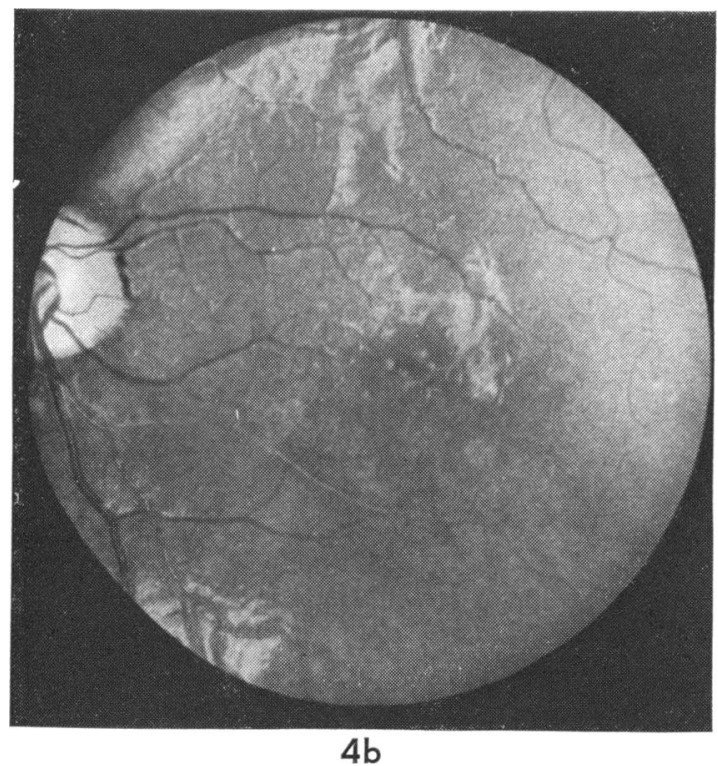

type 2) was isolated from the throat, the CF herpes antibody titre was slightly raised, and an unusually high peripheral eosinophilic count, $8000 / \mathrm{mm}^{3}(8 \times$ $10^{9} / 1$ ), was recorded. Cytomegalovirus and varicella antibody titres were negative.

During the post-partum period nothing remarkable was found in the eyes on routine ophthalmoscopy. At the age of 5 years, however, the central visual acuity of the right eye was found to be slightly decreased, and ophthalmoscopy showed some vitreous opacities and mild preretinal and retinal changes in both eyes. During the 2-year follow-up no obvious progression was observed. The findings in each eye were as follows.

Right eye: The central visual acuity (VA) was 0.7 .
The anterior segment was normal, but some vitreous opacities were seen, particularly in front of the macula. The disc was pale, and the main arteries were narrow, with some sheathing. In the centre of the macula a small white slightly raised intraretinal exudate was found surrounded by dilated capillaries, and another smaller white spot was present temporal to the disc. In the macular area the retina was slightly oedematous, and round the posterior pole the fundus was greyish and glistening, owing to a thin preretinal membrane (Fig. 4a). On the nasal side this was already seen by the optic disc. Several small tufts of neovascularisation were found on the margin of the normal-looking retina. The peripheral retina was atrophic without any visible blood vessels, but the choroid looked normal.

Left eye: The central VA was $1 \cdot 0$, and the media was clear. The optic disc was normal, but the main arteries were narrow and sheathed as in the right eye. Changes in the macula were less pronounced (Fig. $4 b$ ), but some faint greyish spots and streaks were seen in the centre of the macula. Round the posterior pole the retina was glistening, as in the right eye, and the periphery was atrophic and avascular, but neovascularisation was not seen.

Fluorescein angiography of the right eye temporal to the macula showed filling of the main choroidal vessels (Fig. 5a) and of the choriocapillaris (Fig. $5 b$ ) before filling of the retinal artery, and considerable peripheral non-retinal perfusion (Fig. $5 c$ ). Immediately temporal to the macula there was dilatation of the retinal capillaries, with progressive leakage of the dye into the retina (Fig. $5 d$ ). In the midperiphery there was multifocal hyperfluorescence derived from preretinal new vessels (Fig. $5 e, f$ ).

Fluorescein angiographic study of the left eye (Fig. 6a) showed considerable anomaly in the vascular architecture of the macula. There were 


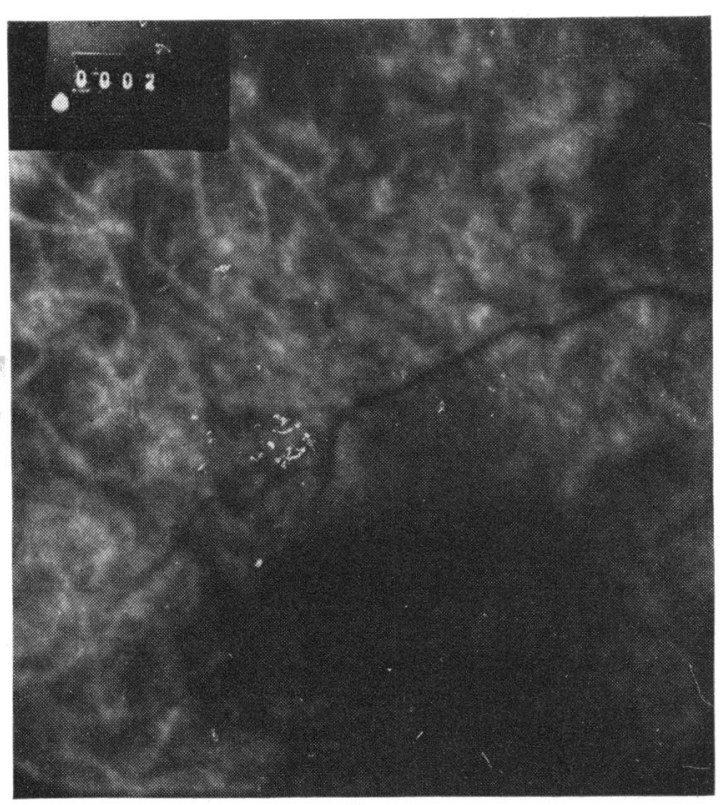

$5 a$

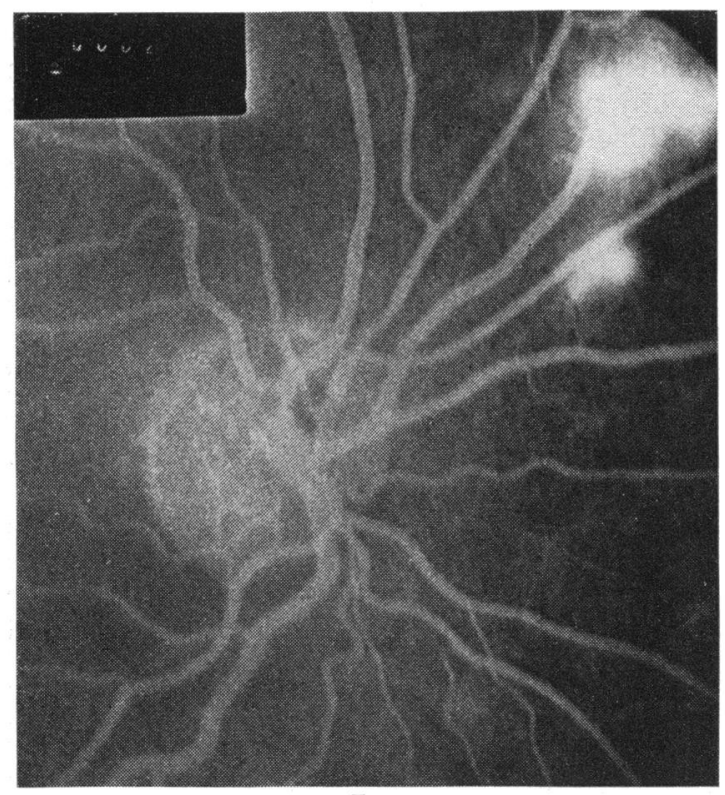

$5 e$

large arterial branches in the close proximity of the fovea and no capillary free zone was present (Fig. $6 b$ ). Very few capillaries were seen temporal to the fovea and some of them were dilated and leaked fluorescein (Fig. 6c). Around the posterior pole normal capillary bed was not perfused (Fig. 6d), and several arteriovenous vessel arcades were seen at the margin of the ischaemic area (Fig. 6c). A

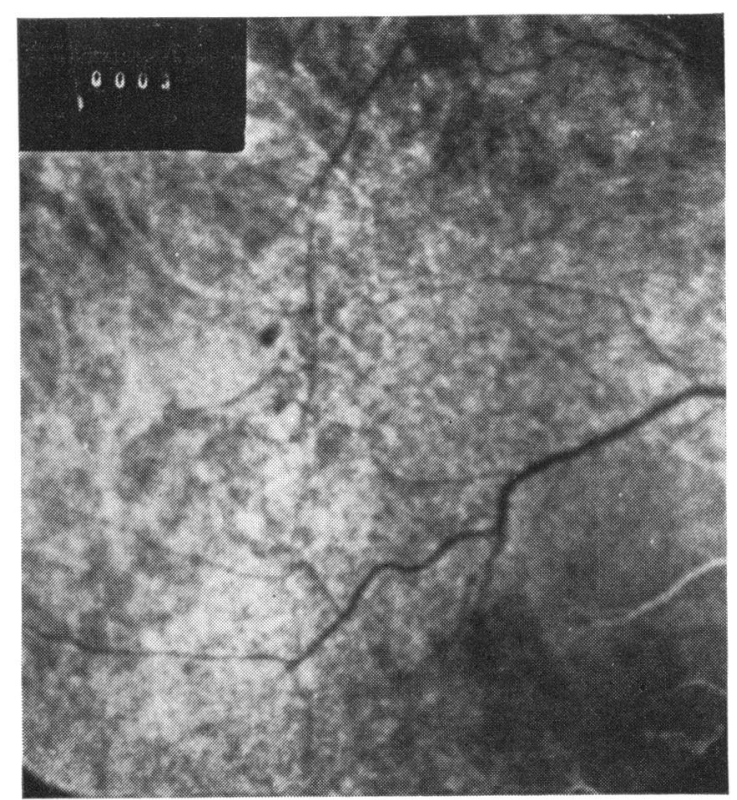

\section{$5 b$}

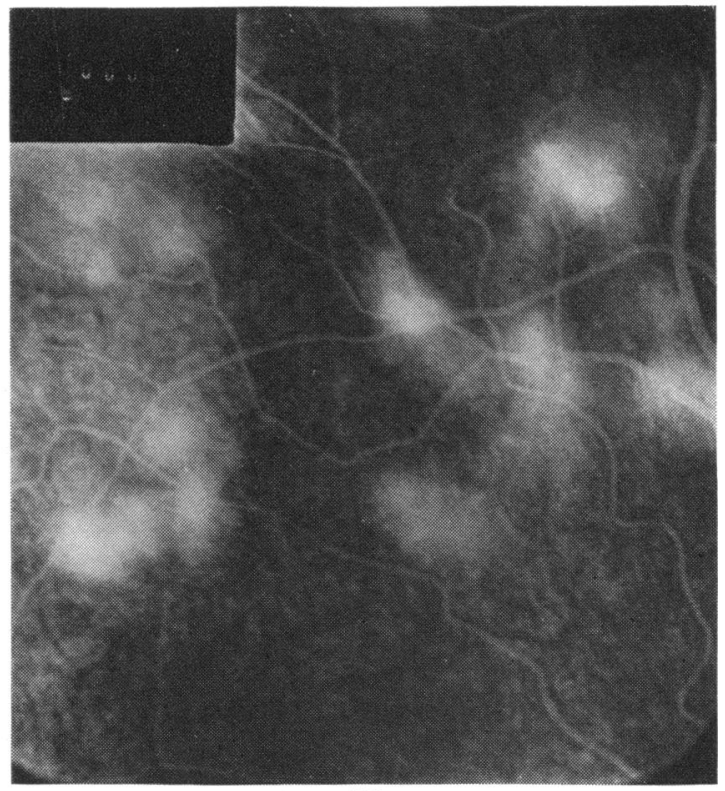

$5 f$

few small leaking areas (Fig. 6e)-presumptive preretinal new vessels-were also seen in the left eye in angiography.

Because of preretinal exudation and neovascularisation laser treatment was carried out on the right eye. Preretinal and leaking vessels were treated directly if possible except in the centre of the macula, and simultaneously a sparse grid of 


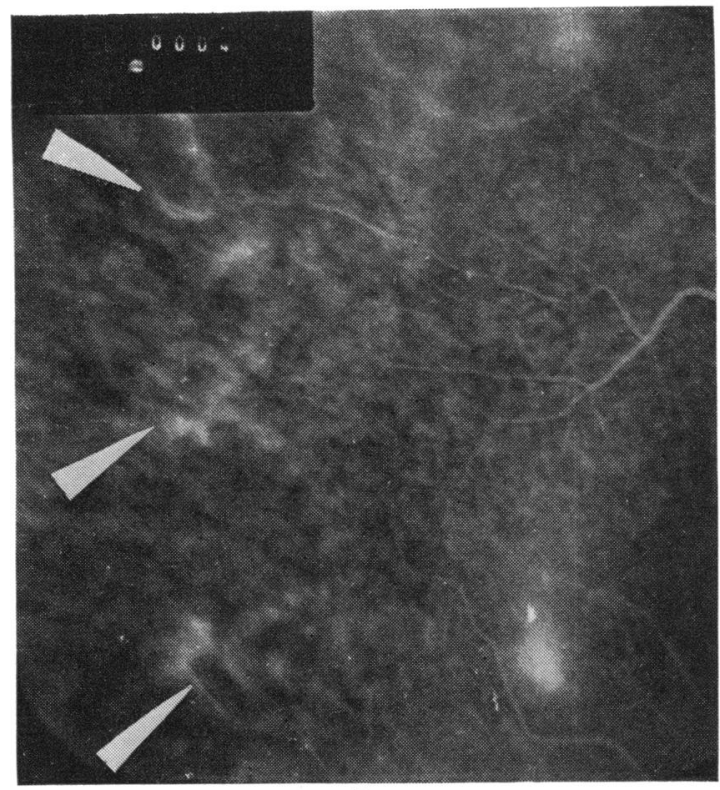

$5 c$

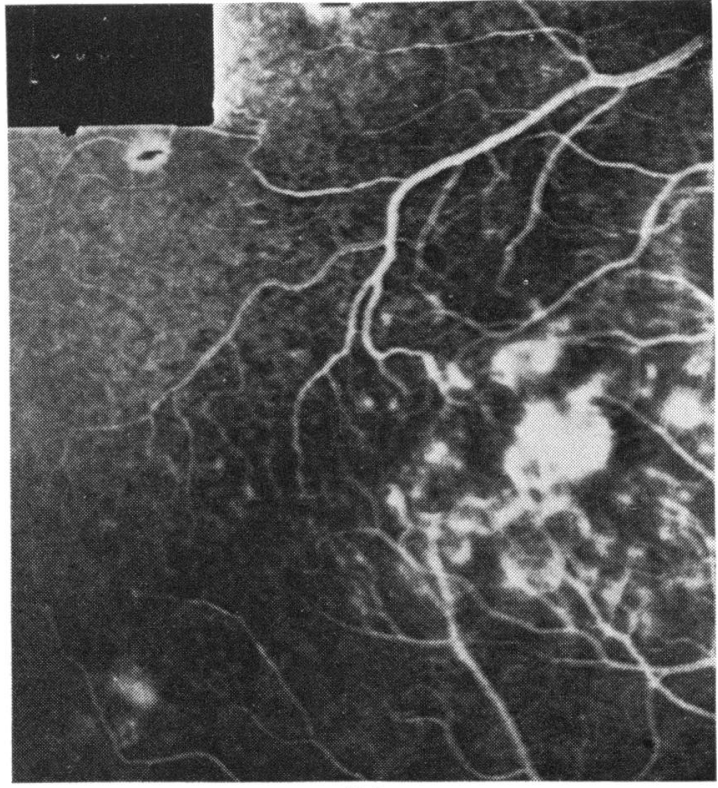

$5 d$

Fig. $5 a-f$ Case 4 Right eye. Choroidal vessels (a) as well as diffuse fluorescence of the choriocapillaris (b) clearly visible owing to retinal and pigment epithelial atrophy. Delayed and slow filling of retinal arteries as compared with choroidal circulation (b). Dilated leaking capillaries on the margin of the non-perfused retina temporal to the macula (c) and in the macula (d) (arrows). (e, f) Pretreatment fluorescein angiogram, late venous phase. Leakage of fuorescein from preretinal vessels superonasally (e) and above the macula (f)

coagulations was applied along the border of the non-perfused retina round the posterior pole. The treatment was carried out in 4 sessions with about one month apart using $1 \cdot 0$ to $0 \cdot 5-\mathrm{mm}$ spot size; 763 burns altogether were applied. During this period visual acuity improved slightly from 0.7 to 0.8 and vitreous opacities decreased. Fluorescein angiography 2 months after the initial treatment showed considerably less leakage of fluorescein as compared with the pretreatment situation (Figs. $5 e, f ; 7 a, b$ ).

\section{Discussion}

HSV ocular involvement in the newborn is easily overlooked, particularly if the general manifestations are absent. The differential diagnosis of herpetic 


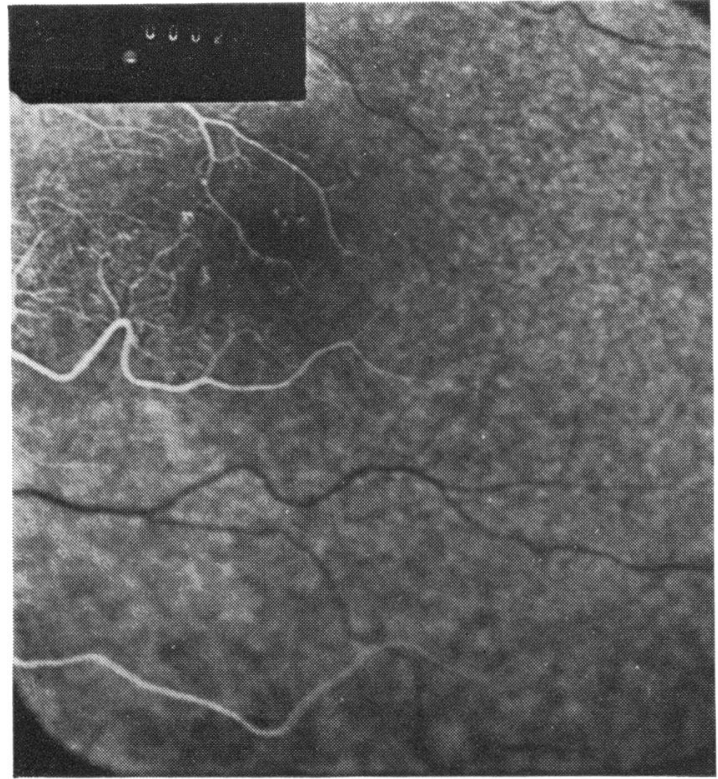

$6 \mathrm{a}$

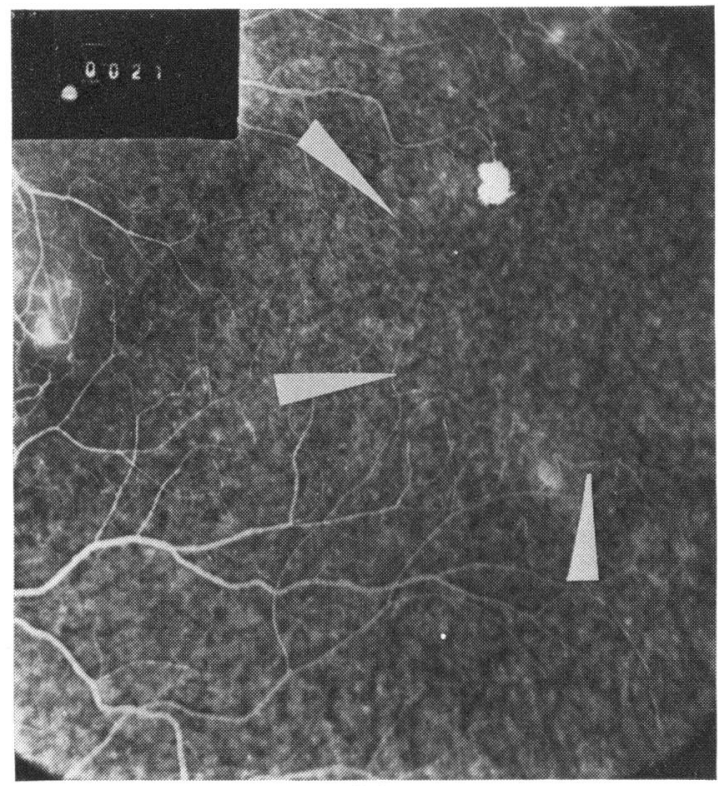

6d

retinitis includes toxoplasmosis, rubella, cytomegalovirus infection, and syphilitic chorioretinitis. In our cases the diagnosis had been confirmed by virus isolation and antibody titration.

Manifest squint in 3 patients may be explained by poor visual acuity in one or both eyes. Case 2 had a deeply amblyopic right eye with no fixation and had been operated on for cosmetic reasons. Atrophy of

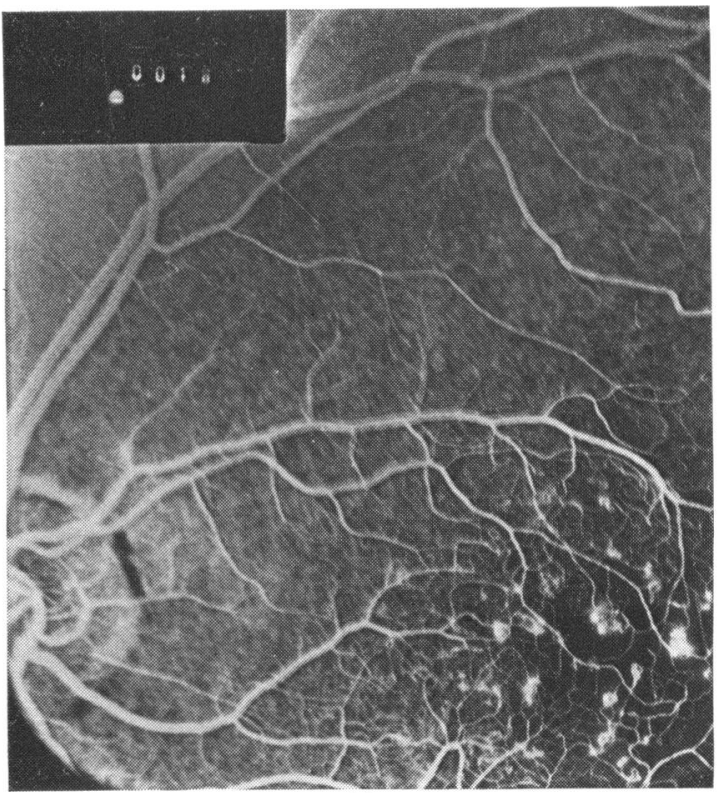

$6 b$



$6 e$

the retinal pigment epithelium could be due to prematurity, as cases 1 and 3 had birth weights under $2500 \mathrm{~g}$, but similar atrophy was also found in case 5 with birth weight within the normal range. One may conclude that we are dealing with sequelae of neonatal HSV retinitis. These include also the thick fibrovascular retinal fold extending into the vitreous in the left eye of case 3. 


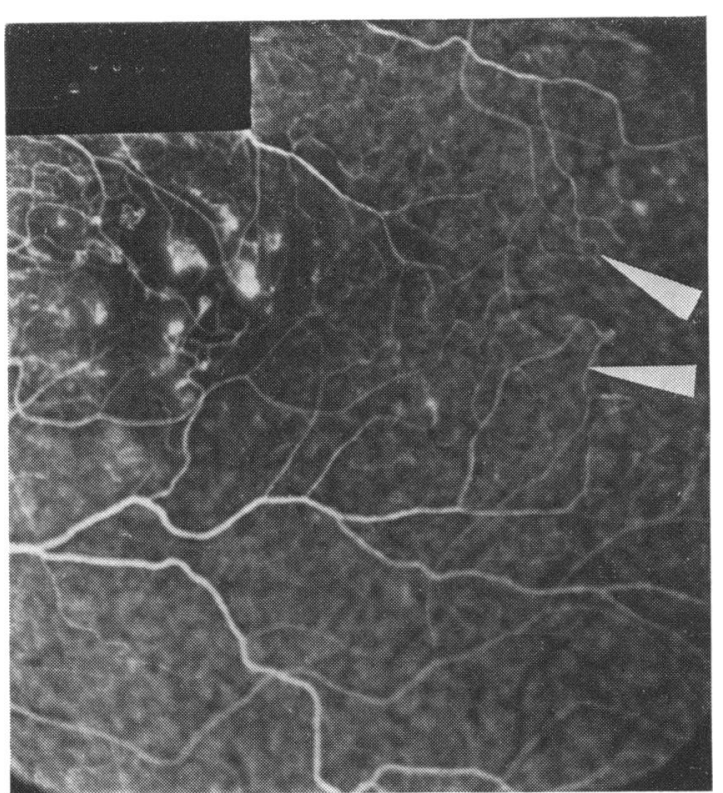

$6 c$

Fig. 6a-e Case 4 Left eye. Good view of choroidal fluorescence even in the macular area (a). Delayed and slow filling of retinal arteries as compared with choroidal filling. (b) Abnormal vascular architecture in the macula with some dilated and leaking capillaries in the centre.

(c, d) Several arteriovenous communications (arrows) on the margin of the avascular retina temporal to the macula. (e) Leaking areas along the course of the inferotemporal veins (arrows)

Fig. 7a, $b$ Same areas as in Fig. 5e, f, 2 months after initial laser treatment. Considerably less leakage than before treatment

The great majority of ocular manifestations in neonatal herpes simplex infections have been described within the first months of life (Hutchison et al., 1975). Ten patients have been described with chorioretinitis detected mostly between 30 and 90 days after birth (Nahmias and Hagler, 1972). In our case 4 the changes were not detected until the age of 5 years.

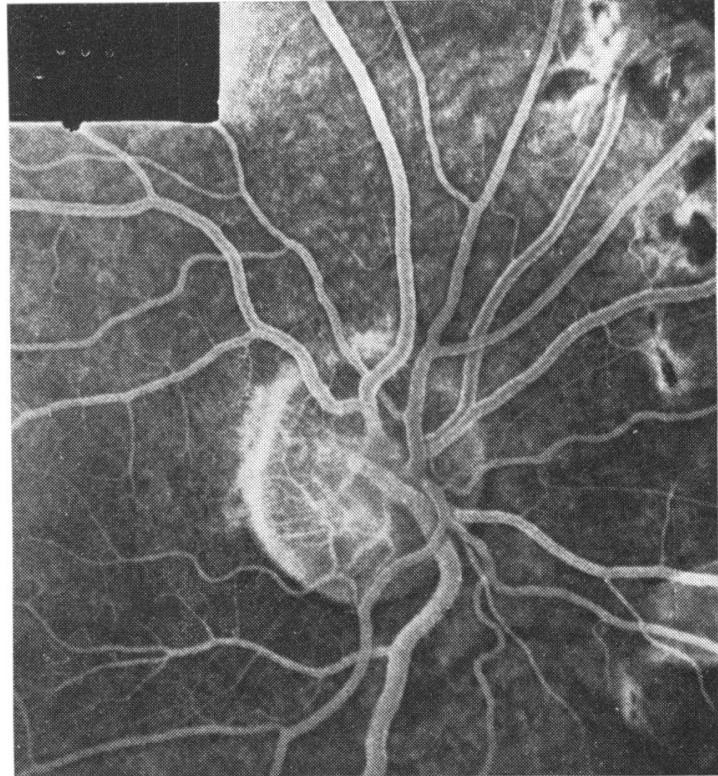

$7 a$

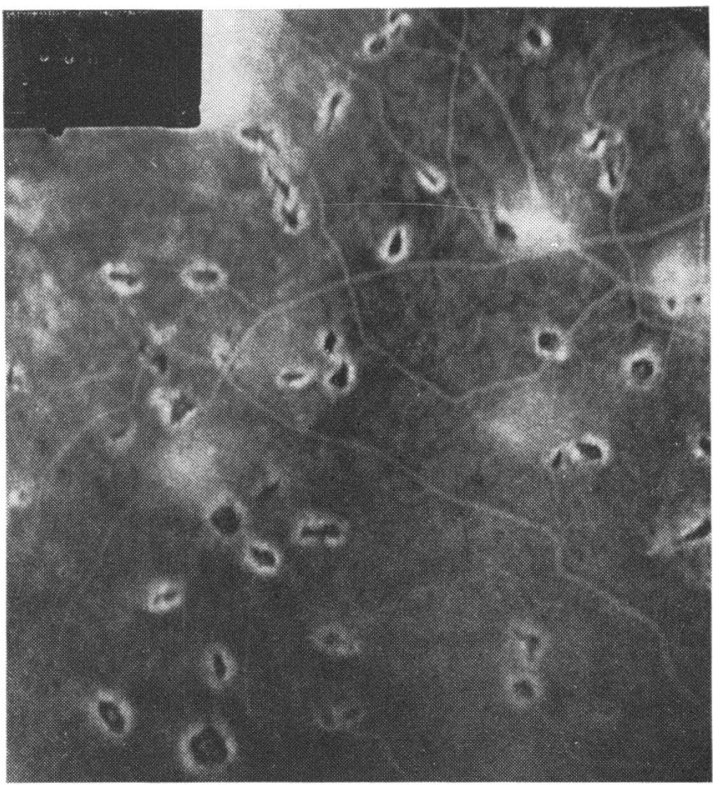

$7 b$

Fluorescein angiographic studies on herpes simplex retinitis have not been reported before. The late changes described in one of our patients are restricted to the retina, whereas the choroid looked normal. This finding is in agreement with the two histopathological studies available (Cogan et al., 1964; Cibis, 1975). Retinal vascular closure found by fluorescein angiography is suggestive of a chronic 
retinal vasculitis. Perivascular inflammatory reaction has also been described in other tissues in herpes simplex infection (Reynolds et al., 1975). Haemorrhagic infarction may therefore be the possible cause of tissue injury in herpes retinitis. Both the limitation of the process to the retina and the symmetrical affection of both eyes are presumptive of an immunological rather than a direct viral infection in this particular case, as Cogan et al. (1964) and Cibis (1975) have suggested. Neither of these authors identified viral inclusions in the retina. The absence of choroidal involvement has also been reported in congenital cytomegalic inclusion disease, in which the condition was primarily a retinal infection with minimal choroidal involvement in the presence of complete retinal necrosis (Tarkkanen et al., 1972).

Preretinal neovascularisation is a common complication in several eye diseases with retinal vascular closure. As in our case 4, new vessels are usually situated at the margin of the ischaemic area. But in this case the new vessel tufts were smaller than in many other diseases, and several were present. Because of the danger of further proliferative changes laser treatment was carried out on the right eye to destroy both neovascularisation and the hypoxic areas round the posterior pole.

Since the clinical course and appearance of herpetic eye lesions may vary, all patients with neonatal herpes simplex infection should have ophthalmic examinations at regular intervals. The ophthalmologist has a crucial role in the early recognition and management of the ocular effects of congenital HSV infection.

\section{References}

Cibis, G. W. (1975). Neonatal herpes simplex retinitis. Albrecht von Graefes Archiv für klinische und experimentelle Ophthalmologie, 196, 39-47.

Cogan, D. G., Kuwabara, T., Young, G. F., and Knox, D. L. (1964). Herpes simplex retinopathy in an infant. Archives of Ophthalmology, 72, 641-645.

Hagler, W. S., Walters, D. V., and Nahmias, A. J. (1969). Ocular involvement in neonatal herpes simplex virus infection. Archives of Ophthalmology, 82, 169-176.

Hutchison, D. S. Smith, R. E., and Haughton, P. B. (1975). Congenita! herpetic keratitis. Archives of Ophthalmo!ogy, 93, 70-73.

Nahmias, A. J., and Hagler, W. S. (1972). Ocular manifestations of herpes simplex in the newborn (neonatal herpes simplex). International Ophthalmology Clinics, 12, 191-213.

Nahmias, A. J., Visintine, A. M., Caldwell, D. R., and Wilson, L. A. (1976). Eye infections with herpes simplex viruses in the neonates. Survey of Ophthalmology, 21, 100-105.

Pettay, O., Leinikki, P., Donner, M., and Lapinleimu, K. (1972). Herpes simplex virus infection in the newborn. Archives in Disease in Childhood, 47, 97-103.

Reynolds, D. W., Stagno, S., and Alford, C. A., Jr. (1975). Chronic congenital and perinata! infections. In G. B. Avery (Ed.) Neonatology, Pathophysiology, and Management of the Newborn, pp. 567-616. Lippincott: Philadelphia.

Tarkkanen, A., Merenmies, L., and Holmström, T. (1972). Ocular involvement in congenital cytomegalic inclusion disease. Journal of Pediatric Ophthalmology, 9, 82-86.

Young, G. F., Knox, D. L., and Dodge, P. R. (1965). Necrotizing encephalitis and chorioretinitis in a young infant. Archives of Neurology, 13, 15-24. 